\title{
Looking Ahead: Part I
}

\author{
Pasquale Commendatore $^{1(\bowtie)}$ and Ingrid Kubin ${ }^{2}$ \\ ${ }^{1}$ Department of Law, University of Naples "Federico II", Naples, Italy \\ commenda@unina.it \\ 2 Department of Economics, Institute for International Economics \\ and Development, WU Vienna University of Economics and Business, \\ Vienna, Austria \\ Ingrid.Kubin@wu.ac.at
}

\begin{abstract}
This Chapter summarises the work carried out during the lifetime of the Action by Working Group I whose main task was to build multiregional NEG models. The main results are briefly presented and some of the questions left open are pointed at. Finally, topics for future research are suggested.
\end{abstract}

Keywords: Multiregional NEG models $\cdot$ Social network analysis $\cdot$ Regional trade flows · Policy issue in NEG models - European regions · Trade agreements

\section{Introduction}

Within the activities of the COST Action IS1104 'The EU in the new complex geography of economic systems: models, tools and policy evaluation' the main objective of the Working Group on 'Economic Geography modelling' has been to provide a modelling strategy to represent the 'EU as a multi-level complex evolving system'. We started from the observation that the process of integration did not fully deliver its promise leaving the economic activity unevenly spread across European regions.

As a modelling strategy, we opted for the New Economic Geography (NEG) approach - originated from Krugman's (1991) contribution - which has proven to be quite fruitful in describing the basic economic mechanisms behind the spatial distribution of economic activity. Briefly, the standard set-up of a NEG model includes an economy with two regions (or countries), two sectors and two factors of production, Dixit-Stiglitz monopolistic competition, CES preferences over the varieties of the manufactured good, factor mobility between the regions, iceberg/multiplicative trade costs. The spatial distribution of the economic activity is the result of the interplay between agglomeration forces - market-access and cost-of-living effects - and dispersion forces - competition and local market size effects (for a more detailed description of the NEG approach, please refer to Chaps. 1 and 2 of this book).

In the following sections, we summarise the research carried out by Working Group I on its main objective: multiregional NEG modelling; then we present some of the main results and pointed at questions left open; finally, we suggest topics for future research. 


\section{Summary of the Research Conducted Within the Action}

Our main research focus has been multiregional New Economic Geography (NEG) modelling. The aim of NEG models is to explain the uneven distribution of economic activity across space driven by factor migration (labour, physical or human capital) governed by interplay of agglomeration and dispersion forces.

In Commendatore et al. (2015a), we reviewed systematically multiregional NEG models recently developed in the literature and compared different modelling strategies. In that survey, we presented a taxonomy of the literature that groups the contributions into two classes: the first category of models follows the standard NEG approach: they adopt CES consumer's preferences leading to an isoelastic demand for each variety and to a fixed mark-up. In this type of models, trade liberalization or integration - modelled as a reduction of 'iceberg' trade costs proportional to the manufactured commodity price favours the agglomeration forces over the dispersion forces. Conversely, the second class of models suggests that trade integration - modelled as a reduction of trade costs which are added to the price - may lead to the prevalence of dispersion forces over agglomeration forces. This feature is obtained by Ottaviano et al. (2002) by simply introducing quadratic consumer's preferences over the manufactured varieties generating linear demands for these varieties and variable mark-ups. In a 'linear' NEG model (see Baldwin et al. 2003) prices fall depending on the number of (local and outside) firms which compete in the local market. This adds a further dispersion force to those operating in NEG models which manifests itself especially in a multiregional context. Indeed, Ago et al. (2006) and Behrens (2011) show in models with a hub-and-spoke structure that centrality delivers a locational advantage to the hub when competition is not too strong (as in standard NEG models) and a locational disadvantage when competition is fiercer (as in linear NEG models). This translate to completely different firms' location patterns and regional policy recommendations. In Commendatore et al. (2015a), we also sketched the analytic structure of a general multi-regional model and we showed how simpler cases can be derived from that general framework.

In other contributions, we put forward simpler standard NEG models (see Commendatore and Kubin 2013; Commendatore et al. 2014, 2015b, c) and linear NEG models (Commendatore et al. 2016, 2017a, b) where the number of regions is assumed to be small (but larger than two) to obtain as much as possible analytic results and numerical simulations easy to interpret. A distinguishing feature of these analyses is the discrete time dynamic framework, which is a set-up able to generate a larger variety of long-term behaviours compared to the continuous time version. We mainly used tools from the mathematical theory of dynamical systems to study the qualitative properties of such multiregional discrete time models.

Behrens (2004, 2005) and Ago et al. (2006) showed that, when demands are linear, there are circumstances - linked to trade costs and local competition - in which one region does not have a sufficient incentive to export the manufactured good to another region. So that different trade patterns may emerge: no trade, unilateral trade and bilateral trade. Commendatore et al. (2017a, b) extend/integrate these contributions. They represent a small trade network composed of three identical regions. In these contributions, three examples have been discussed that can be interpreted as three 
stages of development. In the first stage, since trade costs are very high throughout the economy, all regions are fully autarkic; in the second stage two regions begin to integrate and may engage in unilateral or bilateral trade, while the third region geographically more remote - is still in autarky; finally, in the third stage, when the first two regions are fully integrated, the trade costs between the remote region and one of the other two shrink, so that the remote region and the now more central region engage in trade. The three-region economy takes the shape of a hub-and-spoke trade structure. Within this framework, Commendatore et al. (2017a, b) clarify: how distance and trade costs are related to the existence and direction of a trade link; how trade integration affects the long-term distribution of economic activities and which trade pattern characterises each spatial equilibrium; and, finally, how trade patterns and the spatial distribution of the economic activity are interrelated.

In recent efforts, we applied Social Network Analysis to investigate the statistical properties of the network of trade flows between European regions at the NUTS 2 level and put forward first attempts to provide theoretical underpinnings of such a structure (see Basile et al. 2016, 2017). In Basile et al. (2016), we used a new set of data on regional trade flows and exploited their binary structure and their relative weights to visualize the European regional trade network. Given the limits of the data (partially inferred from other data aggregated at the national and international levels), to reduce the density of the network we used a meaningful threshold cutting off negligible links. This allowed us to detect the higher order statistics via clustering analysis and the main triadic structures via the triad census of the interregional trade links. The latter methodology is typically used to study the local properties of a network - which is a structure composed of nodes (in our case, regions) and relationships linking one node to another node (in our case, trade flows: one in the outward direction, exports; and one in the inward direction, imports). An important property is, for example, the 'third region effect' according to which the existence/absence of a trade link between two regions is contingent upon the presence of (at least) another pre-existing link between one of these two regions and a third region. A triad is a fundamental unit of analysis composed of three nodes and by the possibility of presence/absence of links relating pairwise these nodes. There are 64 possible types of triad that without specific differentiations (related for example to regional sizes or geographical distances) can be grouped into 16 isomorphism classes. In Basile et al. 2016, by using a specific cut off threshold, we calculated for the European trade network the frequencies of these classes and drew interesting insights on the interregional EU trade network. Moreover, we put forward a three-region linear NEG model which is more general compared to those existing in the literature. We assumed that the distance between the regions is not necessarily the same so, differently from other contributions (see for example Ago et al. 2006; and Behrens 2011), we did not impose any specific geography on the possible network structures. Thus, focusing on the short-run with no factor migration, we have been able to derive the conditions, expressed in terms of different combinations of trade costs and distributions of the economic activity, corresponding to each of the 16 possible network structures.

In Basile et al. (2017), we focussed on the role of trade costs in determining the topological structure of the EU network. In dealing with the empirical analysis, to better approximate their broad theoretical meaning, we considered two dimensions of trade 
costs: geographical distance - we created different sub-graphs (i.e. sub-networks) composed of groups of regions differentiated on the basis of regional bilateral distances and the presence of a border effect - we created different sub-graphs distinguishing between regions involved in intra-national or international regional trade. The theoretical part extends Basile et al. (2016) by explicitly differentiating the distances between the regions and exploring how trade costs impact on the frequency of the 64 triadic configurations, examining the likelihood of each configuration. We found correspondence, with some exceptions, between empirical and theoretical results.

\section{Main Results and Open Questions}

\subsection{Main Results}

We focus here on results concerning agglomeration and dispersion patterns characterising the stationary long-term equilibria of some of the multiregional NEG models we have examined during the life time of the Action. Other results are reviewed in Chaps. 1 and 2 of this book. Moreover, readers interested in the mathematical properties of these models can refer to Kubin et al. (2016). In that contribution we stressed that the possible long-term states of the economy are by all means not limited to stationary equilibria.

Concerning three-region models, we found that the presence of a third region matters. In Commendatore et al. (2014), we provided a paradigmatic example: we considered a 3-region footloose-entrepreneur new economic geography model with standard CES preferences. The three regions have a specific geographical arrangement: two of them are symmetric and form an economically integrated area (the Union), the third one is an outside trade partner. Entrepreneurs can freely migrate within the Union, but no factor mobility is allowed between the Union and the third region. Depending on the skill endowment, the market size of the outside region and the different degrees of trade liberalisation - explored in its two aspects of regional integration and globalisation - we found that stationary long-run interior equilibria may exist characterised by an industrial sector unevenly distributed across all regions. Trade integration may lead to agglomeration of industry in only one region via a smooth transition (in contrast to the NEG typical catastrophic scenario).

In a second paper (see Commendatore et al. 2016), we adopted the same geographical arrangement but assumed a quadratic utility function and linear demand functions (for a similar approach see Behrens 2011). This set-up allowed us to compare the NEG and the Heckscher-Ohlin perspectives. According to the standard predictions of the Heckscher-Ohlin framework trade integration leads to specialization, trade diversion and trade creation; however, with factor mobility, it may also lead to agglomeration within the Union, which agrees with the standard NEG result, strengthening the specialization and trade effects of integration. Finally, given the simpler analytical structure following the assumption on preferences, only a stable symmetric equilibrium or full agglomeration (Core-Periphery) equilibria exist.

In other two works, we increased the number of regions to four in a standard NEG model. In the first contribution (Commendatore et al. 2015c), four regions of equal size 
are located along a line, the two regions on the left and those on the right form two countries (or trade blocs) sharing a common border passing through the two regions in the middle. Again, the mobile factor (entrepreneurs) can only migrate within the same country. Due to various geographical impediments to trade the two inland regions (at the extremes of the line) can only access the national market and international trade can only occur between the two bordering regions (at the centre of the line). The specific geography adopted bears on the relative strength of agglomeration and dispersion forces: local firms in the peripheral region face only national competition from firms located in the adjacent central region, whereas the latter face both national and international competition, respectively originating from the peripheral region in the same country and from the bordering region in the other country. On the other hand, a firm located in a central region has access to a larger market selling goods both to the national market (both locally and to the adjacent peripheral region) and to the international market (i.e. to the foreign bordering region). Moreover, in a central region a larger variety of goods are accessible to local consumers. Thus, the market size effect, the price index effect and the competition effect are all stronger in a central region with the strength depending on the size of the manufacturing sector in the bordering region in the other country. The usual NEG sequence (as depicted in the standard tomahawk diagram) occurs with trade liberalization: low trade costs bring dispersion and high trade costs agglomeration. However, a larger variety of patterns can emerge compared with the standard two-region set up: with low trade costs, dispersion involves a larger share of industry in the two central regions; with high trade costs agglomeration could be symmetric - industry agglomerates in the two central regions, thus firms enjoy the full extent of the market size effect - or asymmetric - industry agglomerates in a central region in one country and in a peripheral region in the other country, thus firms in the periphery are sheltered from competition -; with intermediate trade costs, partial agglomeration may occur: industry is agglomerated in one country and dispersed in the other where firms, as in the previous case, find shelter from foreign competition.

In the second contribution (Commendatore et al. 2017c), we differentiated the regions on the basis of their size according to the sequence: small, big, small, big. This set-up allowed us to study the interplay between centrality and local market size effects two different manifestations of the market access effect - which is not possible in other 4-region NEG models. Thus, each country is composed of a small region and a big region. In one country, the small region is peripheral and the large region is central and in the other country, on the contrary, the small region is central and the large region is peripheral. As before, factor mobility is only allowed between regions in the same country. Instead, differently from the previous contribution, we allow for both direct and indirect trade (i.e. between adjacent and non-adjacent regions). Taking into account that additional trade costs are incurred crossing the international border, we differentiated between national and international trade costs. Confining here our discussion to the long-run full agglomeration outcomes (Core-Periphery or CP equilibria), we have been able to find that by varying national and international trade costs, the stability properties of CP equilibria follow patterns which depend on the interplay of three effects: centrality, local market size and competition. Our model includes the standard two-region asymmetric NEG model as a special case (when trade costs between countries are prohibitive). In the two-region set-up, when trade costs take intermediate values, 
agglomeration can only occur in the bigger region (the local market size effect is strong); and when trade costs are low, depending on initial conditions, industry may agglomerate in the smaller region as well (the local market size effect is weak). In our more general four-region set-up, matters are more complicated. Given that agglomeration can only occur within each country, because factors cannot migrate across countries, what can occur is that or all firms end up in the two bigger regions, or in the two smaller regions, or in the two central regions or in the two peripheral regions. The following scenarios are possible: (i) when trade costs are high between countries and low within countries all CP equilibria are stable and are possible long-run outcomes, replicating the standard result which applies to the case of two asymmetric regions; (ii) when we increase national trade costs (without reducing too much international trade costs) simultaneous agglomeration in the two small regions is not possible, again as it was the case in the standard two-region set-up, because of the market size effect; (iii) when we further increase trade costs within countries (or decrease trade costs between countries) simultaneous agglomeration in the two remote regions is not possible. Centrality gains importance. Firms may still end up in the larger remote region which keeps the advantage of a larger size; (iv) further reducing trade costs within countries and letting international trade costs sufficiently high leads to agglomeration only in the bigger regions, as the local market size effect becomes prevalent; (v) instead the same reduction of national trade costs, but in correspondence of low international trade costs leads to agglomeration in the central regions as centrality becomes the prevailing force.

\subsection{Open Questions}

There are a few questions left open deserving to be addressed in future projects:

- Number of regions. We limited our analysis to economies composed of a small number of regions. Given the complicated analytical structure of the NEG approach with a CES utility function, also for this 'simpler' models, it was not easy to interpret all the results.

- Trade Patterns. In the standard model, with finite trade costs, only a trade pattern is possible corresponding to two-way trade between any two regions. By introducing a quadratic utility function leading to linear demand functions, the analysis is made simpler and more analytical results can be derived. Moreover, other issues can be explored given that, for example, with a linear demand, differentiated patterns of trade can emerge (no trade, one-way trade, two-way trade). In fact, considering two regions four trade patterns are possible; when three regions are considered the possible patterns of trade are 64 and so on. We believe that this apparently minor difference represents a powerful tool of analysis.

- Policy issues. We examined a variety of policy issues (tax competition, government expenditure, trade integration, and so on) but, following the large part of the current NEG literature, only considering two or little more regions (for a review on how policy issues are treated in this literature, see Chap. 1 of this book). 


\section{Suggested Topics for Future Research}

Following the previous section on open issues, we would like to draw a few lines for future research:

(i) Multi-regional NEG modelling. We plan to extend the standard NEG model to many regions arranged on a square lattice (for a similar framework see Stelder 2005; Ikeda and Murota 2014; Ikeda et al. 2017). To reconcile computing simplification and real world resemblance, the mobile factor migration process is modelled as a stationary markovian stochastic process. One of the objective of this project is to put forward a platform for simulating multiregional NEG models by using a user-friendly programming language, as for example Python.

(ii) Multiregional NEG modelling. We also plan to extend the linear NEG model to many regions. Given that this type of NEG models is much less treated in the literature more gaps should be filled. In Basile et al. (2016, 2017), we put forward a three-region linear NEG model and explored both theoretically and empirically the probability of the emerging of different trade patterns, depending on trade costs and the degree of competition for a given distribution of the industrial activity (by fixing the number of entrepreneurs). The next step would be allowing for factor mobility and explore the simultaneous evolution through time of industrial location and trade patterns. This would lead to more general cases compared to those discussed in Chap. 2 of this book. A final more ambitious step would be to consider a large number of regions and to study the effects of local and global shocks, affecting trade costs, on the trade network structure in the short run and on the distribution of economic activities and in the endogenous formation of trade network structures in the long run. Notice that a complementary problem has been studied in the literature: Countries may have an economic incentive - fixed in the short-run - to create bilateral trade agreements, this leading to the formation of a free trade agreement network (see Furusawa and Konishi 2007). It would be interesting to verify the evolution of such network once the economic incentive is allowed to vary.

(iii) Market structure. We plan to strengthen the link between IO modelling and spatial issues by using linear demand spatial models and departing from the standard monopolistic competition set-up generally adopted in NEG modelling.

(iv) Policy issues. Very much connected with the other three lines of research, another project would address specific policy issues: impact of creation/resolution/ modification of trade agreements; impact of EU policies; impact of local government policies; regulations related to environmental issues, and so on. As an example, a three-region linear NEG model could be fruitfully used as tool of analysis to clarify the possible effects of Brexit (the withdrawal of the UK from the EU) on trade flows between the most important economic areas involved - Britain, the EU and United States - and on their citizens welfare. The model would be an extension of the linear NEG model with two regions of asymmetric sizes developed by Okubo et al. (2014). In our set-up, two large regions (the USA and the EU) may engage in trade between each other and with a third small region (the UK). Alternative trade agreements resulting from EU and UK negotiations translate into 
trade costs of different magnitudes, reshaping trade patterns and long-run distribution of the economic activity between the three economic areas.

\section{References}

Ago, T., Isono, I., Tabuchi, T.: Locational disadvantage of the hub. Ann. Reg. Sci. 40(4), 819848 (2006)

Baldwin, R.E., Forslid, R., Martin, P., Ottaviano, G.I.P., Robert-Nicoud, F.: Economic Geography and Public Policy. Princeton University Press, Princeton (2003)

Basile, R., Commendatore, P., De Benedictis, L., Kubin, I.: An investigation of interregional trade network structures. In: Commendatore, P., Matilla-Garcia, M., Varela, L.M., Cánovas, J. S. (eds.) Complex Networks and Dynamics Social and Economic Interaction. Springer, Heidelberg (2016)

Basile, R., Commendatore, P., De Benedictis, L., Kubin, I.: The impact of trade costs on the european regional trade network: an empirical and theoretical analysis. Rev. Int. Econ. (2017). doi:10.1111/roie.12314, forthcoming

Behrens, K.: Agglomeration without trade: how non-traded goods shape the space economy. J. Urban Econ. 55, 68-92 (2004)

Behrens, K.: How endogenous asymmetries in interregional market access trigger regional divergence. Reg. Sci. Urban Econ. 35, 471-492 (2005)

Behrens, K.: International Integration and Regional Inequalities: How Important Is National Infrastructure? Manchester Sch. 79, 952-971 (2011)

Commendatore, P., Kubin, I.: A three-region new economic geography model in discrete time: preliminary results on global dynamics. In: Bischi, G.-I., Chiarella, C., Sushko, I. (eds.) Global Analysis of Dynamic Models for Economics, Finance and Social Sciences. Springer, Heidelberg (2013)

Commendatore, P., Filoso, V., Grafeneder-Weissteiner, T., Kubin, I.: Towards a Multiregional NEG Framework: Comparing Alternative Modelling Strategies. In: Commendatore, P., Kayam, S., Kubin, I. (eds.) Complexity and Geographical Economics, Dynamic Modeling and Econometrics in Economics and Finance. Springer, Cham (2015a)

Commendatore, P., Kubin, I., Sushko, I.: Typical bifurcation scenario in a three-region identical new economic geography model. Math. Comput. Simul. 108, 63-80 (2015b)

Commendatore, P., Kubin, I., Sushko, I.: Trade agreements and regional disparities. In: Bednar-Friedl, B., Kleinert, J. (eds.) Dynamic Approaches to Global Economic Challenges. Springer, Cham (2016)

Commendatore, P., Kubin, I., Sushko, I.: Emerging trade patterns in a 3-Region linear NEG model: three examples. In: Commendatore, P., Kubin, I., Bougheas, S., Kirman, A., Kopel M., Bischi, G.-I. (eds.) The Economy as a Complex Spatial System: Macro, Meso and Micro perspectives. Springer, Cham (2017b)

Commendatore, P., Kubin, I., Sushko, I.: The dynamics of a three-region model linear NEG model. Commun. Nonlinear Sci. Numer. Simul. (2017a). doi:10.1016/j.cnsns.2017.04.006, forthcoming

Commendatore, P., Kubin, I., Mossay, P., Sushko, I.: The role of centrality and market size in a 4-region asymmetric new economic geography model. J. Evol. Econ. (2017c). forthcoming

Commendatore, P., Kubin, I., Mossay, P., Sushko, I.: Dynamic agglomeration patterns in a two-country new economic geography model with four regions. Chaos, Solitons Fractals 79, 2-17 (2015c) 
Commendatore, P., Kubin, I., Petraglia, C., Sushko, I.: Regional integration, international liberalisation and the dynamics of industrial agglomeration. J. Econ. Dyn. Control 48, 265287 (2014)

Furusawa, T., Konishi, H.: Free Trade Networks. J. Int. Econ. 72, 310-335 (2007)

Ikeda, K., Murota, K.: Bifurcation theory for hexagonal agglomeration in economic geography. Springer, Japan (2014)

Ikeda, K., Onda, M., Takayama, Y.: Bifurcation theory of a square lattice economy: Racetrack economy analogy in an economic geography model, MPRA Paper No. 78120 (2017)

Krugman, P.: Increasing returns and economic geography. J. Polit. Econ. 99, 483-499 (1991)

Kubin, I., Commendatore, P., Sushko, I.: Some dynamical models in regional economics: economic structure and analytic tools. In: Bischi, G.-I., Panchuk, A., Radi, D. (eds.) Qualitative Theory of Dynamical Systems, Tools and Applications for Economic Modelling. Springer, Cham (2016)

Ottaviano, G.I.P., Tabuchi, T., Thisse, J.-F.: Agglomeration and Trade Revisited. Int. Econ. Rev. 43, 409-435 (2002)

Okubo, T., Picard, P.M., Thisse, J.F.: On the impact of competition on trade and firm location. J. Reg. Sci. 54(5), 731-754 (2014)

Stelder, D.: Where do Cities Form? A Geographical agglomeration model for Europe. J. Reg. Sci. 45, 657-679 (2005)

Open Access This chapter is licensed under the terms of the Creative Commons Attribution 4.0 International License (http://creativecommons.org/licenses/by/4.0/), which permits use, sharing, adaptation, distribution and reproduction in any medium or format, as long as you give appropriate credit to the original author(s) and the source, provide a link to the Creative Commons license and indicate if changes were made.

The images or other third party material in this chapter are included in the chapter's Creative Commons license, unless indicated otherwise in a credit line to the material. If material is not included in the chapter's Creative Commons license and your intended use is not permitted by statutory regulation or exceeds the permitted use, you will need to obtain permission directly from the copyright holder.

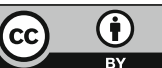

